\title{
Ritmo, tradução e tripartição: Procurando um ponto de encontro entre Meschonnic e Peirce
}

\author{
Rhythm, translation and \\ tripartition: Looking for a meeting \\ point between Meschonnic and \\ Peirce
}

Andrêi Krasnoschecoff*

* Doutorando em Linguística pela Universidade Federal de São Carlos. Bolsista CAPES.

E-mail: andreikras@gmail.com

TradTerm, São Paulo, v.38, fevereiro/2021, p. 169-193

Número Especial - III JOTA

www.revistas.usp.br/tradterm 
Resumo: No presente texto exploramos a possibilidade de encontrar um ponto em comum entre a crítica de Meschonnic $(2006,2010)$ sobre o ato de traduzir, mais especificamente a noção de ritmo, historicidade e subjetividade, e a forma como Peirce entende o funcionamento da linguagem, no caso, a tripartição do signo ícone, índice e símbolo - e as três qualidades de pensamento - primeiridade, secundidade e terceiridade. Também utilizamos Haroldo de Campos $(2011,2018)$ em possíveis pontos em comum com Meschonnic na tentativa de melhor entender as ideias do pensador francês. Usamos versos de $O$ Corvo de Edgar Allan Poe com o objetivo de trabalhar e exemplificar a ideia de ritmo, sempre voltando os olhos para a possibilidade de existência de um ponto em comum entre Peirce e Meschonnic.

Palavras-chave: Meschonnic \& Peirce; O Corvo de Poe; Semiótica; Estudos da Tradução.

Abstract: In the present text we explore a possibility of finding a common point between Meschonnic's (2006, 2010) criticisms regarding the act of translating, more specifically the notion of rhythm, historicity and subjectivity, and the way Peirce interprets the functioning of language, in this case, a tripartition of the sign icon, index and symbol and the three qualities of thought - firstness, secondness and thirdness. It also employs Haroldo de Campos $(2011,2018)$ thinking in possible points in common with Meschonnic to better explain the French thinker's ideas. We assess verses from The Raven by Edgar Allan Poe, with the objective of working and exemplifying an idea of rhythm, always looking at the possibility of a common point between Peirce and Meschonnic.

Keywords: Meschonnic \& Peirce; Poe’s The Raven; Semiotics; Translation Studies.

TradTerm, São Paulo, v.38, fevereiro/2021, p. 169-193

Número Especial - III JOTA

www.revistas.usp.br/tradterm 


\section{Introdução}

Este artigo aborda uma exploração teórica inicial: poderia a teoria semiótica de Peirce conter algum ponto de contato com a poética do traduzir de Meschonnic? Exploramos formas de entender o funcionamento da linguagem dos dois teóricos, procurando observar se elas, em algum ponto, podem se complementar e trazer uma melhor compreensão do funcionamento da linguagem. Iremos começar com a teoria de Henri Meschonnic e em seguida passaremos para a teoria de Peirce, mais especificamente, a questão da tricotomia do signo (ícone, índice e símbolo) e as modalidades de pensamento (primeiridade, secundidade e terceiridade).

Trabalhamos também com Haroldo de Campos que, assim como Meschonnic, estuda problemas de tradução dentro da linguagem poética, resultando em possíveis concordâncias, ou aproximações de ideias, colocando o tradutor e o ato de traduzir em lugares diferentes. Lembrando que, com Meschonnic, trabalhar tradução é também trabalhar a linguagem, testar teorias linguísticas. A maneira como o crítico pensa o processo de tradução possibilita uma forma diferente de olhar para a linguagem, criando um ponto de contato para nos aproximarmos da teoria dos signos de Peirce; mais especificamente, pensando na tradução intersemiótica. Não afirmamos, porém, de forma alguma, que Meschonnic e Peirce necessariamente concordem. Podemos dizer que o presente trabalho se encontra na metodologia do jogo de espelhos (MARTINS 2020), que segundo a autora seria:

uma forma de trabalho intelectual que coloca frente a frente diferentes autores em busca de um diálogo possível. Denomino essa estratégia metodológica de 'jogo de espelhos' ('play of mirrors'), que entendo ser de caráter indutivo, interpretativo e tributário do paradigma indiciário (GINZBURG 1989, apud MARTINS 2020: 2)

TradTerm, São Paulo, v.38, fevereiro/2021, p. 169-193

Número Especial - III JOTA

www.revistas.usp.br/tradterm 
Observaremos trechos do poema The Raven (1845), de Edgard Allan Poe, e duas traduções em português para exemplificar as teorias ${ }^{1}$, sendo este presente texto um exercício teórico.

Quando se traduz uma obra de arte, a simples troca de palavras de um idioma para outro não significa de fato que uma boa tradução tenha sido feita, traduzir envolve outros aspectos. Estamos aqui utilizando a nomenclatura de Meschonnic (2010), saindo do domínio do 'signo', e entrando no domínio do 'discurso'. Precisamos esclarecer um ponto: quando Meschonnic (2010) se refere à linguagem poética, ele não está fazendo distinção entre romance e poesia:

Digo poema para toda a literatura, não somente no sentido restrito habitualmente para a 'poesia' por oposição ao 'romance', abafando-o sem mesmo tomar conhecimento da ausência de distinção entre a poesia e o verso, com a redução da poesia a um gênero (MESCHONNIC 2010: xviii).

Analisamos a seguir a noção de historicidade meschonniciana, fazendo um paralelo, ou um jogo de espelhos, com o pensamento de Haroldo de Campos.

\section{Meschonnic e Haroldo de Campos: possíveis pontos em comum}

0 tradutor, poeta e linguista francês Henri Meschonnic traz um olhar diferente sobre tradução e ao mesmo tempo sobre o funcionamento da linguagem, pois para ele a tradução é o melhor lugar para examinar a Teoria da Linguagem na qual se apoia. A tradução (que deve ser entendida como ação) demonstra os pontos fracos da teoria, na qual ação e teoria caminham juntas. Em sua crítica sobre como a tradução deve ser entendida, enfatiza a importância do ritmo.

\footnotetext{
${ }^{1}$ Nosso projeto de doutorado pesquisa a tradução intersemiótica desse poema para um jogo eletrônico.

TradTerm, São Paulo, v.38, fevereiro/2021, p. 169-193

Número Especial - III JOTA

www.revistas.usp.br/tradterm
} 
Ritmo é um conceito que não pode ser trabalhado/entendido como uma ideia isolada, mas como uma espécie de nó, entrelaçado com outros nós tecendo a rede do pensamento de Meschonnic. Questionamos como olhar para a linguagem, indagação estratégica para a linha de raciocínio escolhida.

Como olhar para a linguagem? Podemos pensar na diferença entre a linguagem do cotidiano e a linguagem artística. Temos a linguagem poética como motor criador da própria linguagem, que por sua vez afeta os indivíduos:

A linguagem poética como a linguagem que é própria do ser humano, mesmo porque é nela e através dela que se constrói e se inventa, continuamente, o pensamento (MESCHONNIC 1989, 2010, apud MARTINS 2019: 123), i.e., é com ela que o ser humano se inventa e se reinventa continuamente como pessoa. A linguagem poética põe em questão a existência diferenciada de algo que se chamaria linguagem do cotidiano, já que o poético transita, em fluxo contínuo, entre o falado e o escrito, entre os falares do dia a dia e a escritura propriamente dita, tornando-se esta verdadeiramente genuína na medida de sua comunicação com aquela, e da tradução que se torna inerente a esse diálogo (MARTINS 2019: 123).

A linguagem deve ser entendida como um fluxo que olha para si mesma, transformando-se e, apesar da diferença entre linguagem poética e linguagem coloquial, as duas se contaminam e se retroalimentam:

A tradução da linguagem está num modo da linguagem não terminológica. Quer dizer que, contrariamente à ideia divulgada que opõe literatura e poesia à linguagem comum, elas estão justamente na linguagem comum. Um discurso. Não da língua. 0 discurso científico se identifica ao máximo com a língua. 0 essencial é o referente, que é preciso conhecer. Mas na literatura e diversidade das obras, existe antes o primado empírico do discurso sobre a língua. Este primado passa pelo da rítmica, da prosódia, da polissemia, banal na linguagem comum e, de maneira nenhuma definitório da coisa literária, como acreditam alguns atrasados que creem fazer diferir o sentido, mas excluem a poética - os desconstrucionistas. A literatura, à diferença do que não é literário, constrói e inclui sua situação e seu referente (MESCHONNIC 2010: 2627).

TradTerm, São Paulo, v.38, fevereiro/2021, p. 169-193

Número Especial - III JOTA

www.revistas.usp.br/tradterm 
Não estamos afirmando que a distinção seja inútil, ela existe de fato, é uma diferença material, são estruturas e construções diferentes; porém, apesar da diferença, há extrema flexibilidade e troca entre as formas de linguagem. Além do fluxo da linguagem poética conversando com a linguagem do cotidiano, temos também o fluxo interno das obras de arte. Textos que se autorrefereciam.

Utilizamos o termo 'tradução', porém não estamos fazendo justiça ao processo, falta explicar melhor, pois o pensamento de Martins navega em direção à historicidade. Esse é um aspecto que Meschonnic (2010) também acredita que deva ser considerado ao traduzir, e Martins (2019: 140-141) demonstra pelo menos duas maneiras de entender a historicidade. Primeiro examina-se uma forma de traduzir "que se faz transversalmente, no interior do próprio fenômeno cultural, enquanto devoração - podemos ver aqui fenômenos que remetem ao que Andrade (2011) denominou canibalismo e antropofagia" para então, posteriormente, trazer a tradução para a contemporaneidade, apontada como um segundo viés do que seria a historicidade.

Explicando melhor a segunda forma de entender a historicidade, ao trazer o texto para a contemporaneidade é que se cria a possibilidade de trazer, ou recuperar, a força poética original do texto. Não se trata de um simples arranjo de vocabulário, trocar palavras velhas por palavras novas, mas (re)colocar a força da criação (criatividade) no ato de traduzir, ou como lembra Martins (2019: 129), é ir em direção ao Recitatif ${ }^{2}$. Encontramos pensamento aproximado na ideia de Haroldo de Campos, que iremos expor a seguir.

Haroldo de Campos (2018) cita a importância do 'corte paidêmico', operação poundiana de trazer o texto para o presente. Dessa forma são retirados do texto elementos que estorvam a leitura. 0 foco aqui é encontrar

\footnotetext{
2 Recitatif é um termo meschonniciano. Em uma explicação resumida, o exemplo dado por Meschonnic (2006/1989 apud Martins, 2019: 128-129) é o da descaracterização da Bíblia em suas traduções. Originalmente a Bíblia teria um tom mais dramático e perfomativo, uma configuração recitativa. Com as traduções, o texto bíblico perde sua força poética, tornandose uma simples narrativa.
}

TradTerm, São Paulo, v.38, fevereiro/2021, p. 169-193

Número Especial - III JOTA

www.revistas.usp.br/tradterm 
uma tradição viva no texto, facilitando assim a leitura do leitor atual. Outra expressão, também trazida de Pound, encontrada nos textos de Campos (2018: 18) é o Make it new: "A ordenação do conhecimento de modo que a próxima pessoa (ou geração) possa, o mais rapidamente, encontrar sua parte viva, e venha a perder o mínimo possível de tempo com questões obsoletas" (CAMPos 2018: 18). A atualização também se faz necessária, pois tanto Haroldo de Campos quanto Henri Meschonnic entendem o ato de traduzir um texto poético como uma atividade próxima, se não igual, à atividade de escrever um texto poético. Ao mesmo tempo em que o texto traduzido é posterior ao texto fonte, perdendo assim a capacidade de se conectar com o imediato da criação original, a tradução acaba se tornando um novo texto, conectado assim a um novo contexto. Lidamos, portanto, com a criação de algo novo, outro texto original.

Para Haroldo de Campos (2011: 10), ao criar, o tradutor deixa de fazer uma tradução servil. Conforme escrevia e traduzia, o autor criou neologismos (transcriação, transluciferação, transtextualização e reimaginação, no caso da poesia chinesa), pois tinha

uma insatisfação com a ideia 'naturalizada' de tradução, ligada aos pressupostos ideológicos de restituição de verdade (fidelidade) e literalidade (subserviência da tradução a um presumido 'significado transcendental' do original.

Assim sai das traduções neutras (no caso de traduções literais) ou servis para entrar na tradução criativa. Ao olhar para a questão de traduzir arte, Campos (2018: 33) cita a 'fragilidade da informação estética': "Enquanto a informação documentária e também a semântica admitem diversas codificações, [...] a informação estética não pode ser codificada senão pela forma em que foi transmitida pelo artista". A informação estética não pode ser separada de sua realização. Meschonnic (2010: 30-31) também aponta para o problema da forma na tradução:

Temos de distinguir entre desperdício e traição, e a transformação.

A forma do sentido permanece em sua língua, como sua fonologia. É

TradTerm, São Paulo, v.38, fevereiro/2021, p. 169-193

Número Especial - III JOTA

www.revistas.usp.br/tradterm 
um desperdício, não uma traição. Ainda o que passa, longe de depender da natureza das coisas, será diferente segundo a concepção que se tem ao mesmo tempo do sentido, e do modo de passagem. Muda-se necessariamente de fonologia na mudança da língua. Mas se um discurso fez de sua fonologia valores de discurso e não apenas valores da língua, o resultado será outro.

Como resultado, tem-se a importância da busca pelo ritmo, de olhar para o texto como um discurso. Pode-se perder o ritmo original devido às diferenças de idioma, mas essa busca é uma tentativa de atenuar tal perda.

A manobra tradutora acaba por ser também crítica, pois seleciona o que o tradutor crê que seja relevante para o leitor. É um posicionamento do tradutor, então entendido como um sujeito, deixando de ficar nas sombras, não mais escondido no processo de tradução. Tanto Meschonnic (2010) quanto Campos (2018) esbarram na questão crítica da tradução. É um deslocamento na forma de entender o lugar ocupado pelo tradutor em seu ofício. Existem outros tipos de deslocamentos, como vemos a seguir.

Por ser um sujeito, o tradutor assume um discurso que não é seu, incluindo um ritmo próprio, ligado à subjetividade desse tradutor. Simultaneamente, devemos notar a presença do texto. Meschonnic faz uma inversão, conforme Neumann (2013: 9, destaques do autor):

Em seu texto 'Oui, qu'appelle-t-on penser?', em Dans le bois de la language, o autor afirma que é o poema que faz o poeta, não o poeta que faz o poema. Ainda no mesmo texto, o autor postula que um poema nos inventa, ele inventa quem o escreve, e inventa quem o lê.

Podemos entender, então, que ao mesmo tempo em que há a questão da presença do ritmo do enunciado produzido pelo tradutor, também há o ritmo presente no texto fonte. A existência do ritmo do texto chama para a existência de um corpo do texto. Para deixar de entender a linguagem e seu funcionamento sob a sombra do signo ${ }^{3}$, é necessário olhar para o texto como

\footnotetext{
${ }^{3}$ Meschonnic usa o termo 'signo' como crítica: a maneira que se trabalha a linguagem, dividindo-a em categorias ao invés de compreendê-la dentro do discurso, à maneira como Benveniste (2006: 82) entende.
}

TradTerm, São Paulo, v.38, fevereiro/2021, p. 169-193

Número Especial - III JOTA

www.revistas.usp.br/tradterm 
uma unidade completa, acarretando a existência de uma subjetividade do poema. Assim a tradução de uma obra poética se transforma em um "discurso assumido por outrem, que carrega consigo um ritmo próprio, uma tonalidade subjetiva própria e - ao se juntar com palavras outras - uma rítmica diferenciada" (MARTINS 2019: 128).

A presença da subjetividade chama a atenção. 0 pensamento de Meschonnic provoca uma reflexão: o texto também pode ser sentido. Se trabalhamos com a historicidade, atualizando o texto, comunicando-o com os outros textos, e se o tradutor imprime seu ritmo no texto (o encontro da subjetividade no texto do tradutor em relação com a do texto fonte), estamos além da gramática, do signo, das classes que Meschonnic questiona. Em qual situação estaríamos então?

Passaremos para a teoria de Peirce, trazendo uma frase de Julio Plaza (2018: 21), ao iniciarmos o próximo passo deste artigo: nosso pensamento é, por natureza, intersemiótico.

\section{Tradução intersemiótica e as categorias de Peirce}

"Como se pode ver, o próprio pensamento já é intersemiótico" (PLAZA 2018: 21). Plaza utiliza muito a teoria semiótica de Pierce para chegar a tal conclusão. Exploraremos a teoria de Peirce começando pelas categorias universais, seguindo posteriormente com o conceito de intersemiose.

As categorias universais são tentativas de diferentes pensadores, em distintas épocas, para estruturar a multiplicidade de fenômenos que captamos e interpretamos, "Espaço e tempo, por exemplo, são dois fenômenos que, na física e mesmo na filosofia, foram considerados como categorias universais por serem irredutíveis a outros fenômenos na cognição humana" (NÖTH e SANTAELLA 2019: 37). Peirce chegou a três categorias universais, as quais chamou de primeiridade, secundidade e terceiridade.

TradTerm, São Paulo, v.38, fevereiro/2021, p. 169-193

Número Especial - III JOTA

www.revistas.usp.br/tradterm 
Com a primeiridade temos a virtualidade. Peirce aponta a primeiridade como o lugar das possibilidades. Estamos lidando com fenômenos que são "meras possibilidades ainda não existentes (porque a existência é determinada por um lugar determinado no tempo e no espaço)" (NÖTH e SANTAELLa 2019: 37). Peirce entende que os fenômenos, em sua primeiridade, ainda não foram associados a nenhum outro fenômeno, por isso mesmo não estão delimitados por associações e, portanto, são mais propensos à liberdade. Fenômenos na primeiridade ainda são impressões, sensações imediatas, por isso, ainda nebulosas, difíceis de determinar.

Quando um primeiro fenômeno se une a um segundo fenômeno, estamos na secundidade:

Ele é a categoria dual dos fenômenos, ou seja, destes em relação a outra coisa, é aquilo que existe e, para existir, chama por algo como tempo e espaço, categorias dos fatos do seu aqui e agora, da ação e reação, do esforço e resistência, da realidade e da experiência do real (NÖTH E SANTAELLA 2019: 38).

Com a terceiridade, temos uma relação com o geral:

A terceiridade é a categoria do geral, da continuidade e da mediação entre um primeiro e um segundo (CP 1337-349, c. 1875) 0 geral é um fenômeno da terceiridade porque generalidade implica continuidade. Ela é também a categoria da semiose dos signos, da representação, da comunicação, das leis, das regras, da necessidade, do hábito e da síntese (NöTH E SANTAELLA 2017: 38).

Tais categorias são presentes na teoria dos signos de Peirce. A tríade ícone, índice e símbolo está ligada às categorias acima citadas.

\section{1. Ícone, Índice e Símbolo}

Segundo a lógica peirceana, nosso pensamento é preenchido por signos, porém o signo é categorizado de acordo com a relação estabelecida entre signo e objeto: o símbolo, o índice e o ícone. De forma resumida, os ícones são "signos que operam pela semelhança de fato entre suas qualidades, seu

TradTerm, São Paulo, v.38, fevereiro/2021, p. 169-193

Número Especial - III JOTA

www.revistas.usp.br/tradterm 
objeto e seu significado" (PlaZA 2018: 21-22). Eles deflagram sentimentos, estão diretamente ligados à qualidade. Temos de tomar cuidado, porém, quando procuramos por um ícone puro, pois ele seria um "mero quase-signo não comunicável" (NöTH e SANTAELLA 2019: 51). Quando lidamos com um ícone, ele já caminha um pouco para o índice, pois possui uma materialidade. Os índices operam "pela contiguidade de fato vivida” (PlAZA 2018: 22).

O Índice é, então, "um signo determinado pelo seu Objeto Dinâmico 4 em virtude de estar com ele em relação real" (PlazA 2018: 22). Uma fotografia seria um exemplo de um índice se considerarmos que, apesar da presença da iconicidade, ou seja, a semelhança, presente na imagem, a fotografia é o resultado da captura de algo que estava fisicamente na frente à câmera. O símbolo seria algo que depende de uma memória, um hábito, ou algo relacionado a uma lei ${ }^{5}$.

Plaza (2018: 22) aponta o signo, seguindo essa lógica triádica, como um processo. Um mesmo signo pode conter essas três características, com pesos diferentes. Dentro desse raciocínio, como nosso pensamento é construído por signos, e como eles possuem a capacidade de operar como índice, símbolo e ícone, nosso pensamento se dá necessariamente por signos. A capacidade de intersemiose é algo intrínseco do signo.

Peirce entende que o signo é composto por três elementos: o signo, o objeto e o interpretante ${ }^{6}$. 0 signo seria uma materialidade representando outro algo, e está no lugar daquilo que substitui; o objeto é o que o signo representa, aquilo a que o signo se refere, por fim, o interpretante, que seria o efeito que surge na mente de um possível intérprete, fruto da relação entre signo e objeto.

É necessário apontar para o fato de a "classificação dos signos que aí se apresenta não é uma classificação aristotélica no sentido de que cada signo

\footnotetext{
${ }^{4}$ Segundo Plaza (2018: 21) para Pierce o signo representa um objeto, porém existem dois tipos de objeto: o Objeto Dinâmico é o objeto no mundo e o Objeto Imediato é o objeto tal como é representado.

${ }^{5}$ Não lei no sentido legal, jurídico, mas, por exemplo, se um grupo determina que certo desenho significa algo, tal relação pode ser considerada uma lei.

${ }^{6}$ De forma resumida, o signo (ou representamen, usando a nomenclatura de Peirce) é o que representa o objeto, criando assim um interpretante; o objeto seria objeto no mundo, e o interpretante seria a interpretação, ou o que se entendeu do signo.
}

TradTerm, São Paulo, v.38, fevereiro/2021, p. 169-193

Número Especial - III JOTA

www.revistas.usp.br/tradterm 
só pertence a uma única classe. 0 que Peirce descreve é um sistema no qual uma classe pode incluir aspectos de um signo de outra classe" (NöTH e SANTAELLA 2019: 48). Resumindo: um signo que possui característica de terceridade pode conter signos com características de secundidade e/ou primeiridade, assim como um signo com característica de secundidade pode conter signos com características de primeiridade. 0 inverso não pode ocorrer, um signo de primeiridade não pode conter elementos de secundidade ou terceiridade.

Outra observação que talvez ajude a explicar a questão de como caracterizar o signo: "A Mente (ou semiose) é um processo de geração infinita de significações, razão pela qual aquilo que era um Terceiro numa dada relação triádica passa a ser um Primeiro numa outra relação triádica" (NETTO 2014: 66). Sendo assim, segundo Teixeira Coelho Netto (2014), depende do contexto em que o signo se encontra, e como olhamos para ele, para podermos determinar o que ele é. É uma flexibilidade relativa. A noção de signo também muda: não estamos pensando nas palavras, mas em qualquer coisa que gere uma impressão na mente de alguém, seja um som, uma palavra, um texto, imagem, aroma ou movimento.

0 entendimento de Peirce sobre o funcionamento da mente permite entender que a tradução é um ato mais comum do que imaginamos. Constantemente traduzimos o impulso captado pelos órgãos sensórios em signos. Quando entramos em contato com certos fenômenos, ainda estamos lidando com sensações indefinidas para depois ser transformado em algo inteligível.

Se a linguagem poética transita entre o falado e o escrito, temos um espaço para entender a presença do som, participando na construção de significados. Não é difícil caminhar para a presença de imagens no processo artístico, onde o verbal, o visual e o sonoro se unem na construção de significados. Lembremos que Meschonnic não se refere ao som, ou apenas a ele, quando fala da oralidade, esta faz parte de um conjunto maior de considerações. Tal lacuna nos leva entender a natureza da linguagem como algo intersemiótico.

TradTerm, São Paulo, v.38, fevereiro/2021, p. 169-193

Número Especial - III JOTA

www.revistas.usp.br/tradterm 


\subsection{O Processo de Semiose}

Abordaremos neste segmento o processo de semiose. Inicialmente vamos esboçar o conceito de signo, o qual, como veremos, funciona também como um processo.

Ao explicar o funcionamento do signo, Peirce adota a seguinte nomenclatura em seus estudos posteriores:

O signo ou [...] é o primeiro que se relaciona a um segundo, denominado objeto, capaz de determinar um terceiro, chamado interpretante, numa definição simplificada, o signo é algo que 'representa alguma coisa, seu objeto' (CP 2.228, c. 1897) e assim produz um efeito na mente de um intérprete ou usuário, efeito que Peirce chama de interpretante do signo (NöTH e SANTAELLA 2017: 39. Destaques dos autores).

Winfred Nöth e Lúcia Santaella (2017: 39) apontam que Peirce define o signo não como uma classe de coisas, mas como o elemento de um processo, denominado 'semiose'. No processo de semiose o signo ao mesmo tempo serve como um mediador e produtor de efeito cognitivo sobre o intérprete:

Essa 'ação do signo' não é ação exclusiva do intérprete do signo, embora um intérprete seja necessário para o signo poder realizar o seu potencial semiótico. Isto se aplica porque, ao estar no lugar do seu objeto, o signo mesmo adquire o poder de produzir um efeito de interpretação. Mas 'nada é signo se não é interpretado como signo' diz Peirce (CP 2308, 1901). Com isso, ele se refere ao signo atualizado, um signo concreto num processo que resulta em um interpretante, quando signo, de fato, realiza sua função de signo.

Entendemos assim que o funcionamento do signo depende tanto da forma como foi construído, quanto daquela com que foi recebido pelo intérprete. Esses tendem a ser convidados pelas obras artísticas a romper com processos que geralmente ocorrem no cotidiano, podendo trazer um espírito de jogo que permite interpretações ausentes em outro tipo de produto ou processo. A obra possui um corpo e uma historicidade própria, recuperando os

TradTerm, São Paulo, v.38, fevereiro/2021, p. 169-193

Número Especial - III JOTA

www.revistas.usp.br/tradterm 
conceitos de Meschonnic. Essa noção de historicidade é que permite supor uma possível aproximação entre Peirce e Meschonnic.

\section{Traduções do poema}

Ao examinar o poema $O$ Corvo, surgem questões do descontínuo (estruturais), assim como elementos voltados para a historicidade, símbolo (a figura do corvo) e ritmo (a inconstância do eu lírico).

Observamos no poema um exemplo das diferentes dimensões da língua. Temos, conforme Paulo Henriques Britto (2019: 38), uma estrutura métrica incomum, um octâmetro trocaico, que sugere um tom hipnótico, mesmo no inglês: “O termo 'trocaico' refere-se a 'troqueu', o pé (isto é, a célula métrica) composto por duas sílabas, sendo a primeira tônica e a segunda átona”. O refrão é a metade, um tetâmetro trocaico, quatro sílabas ao invés de oito. Tal divisão forma células rítmicas que se estendem por todo o poema, com poucas variações durante o percurso. Tal estrutura era rara na época:

\footnotetext{
Para se ter ideia da estranheza que tal metro deve ter causado nos seus primeiros leitores, lembremos que, em mais de $90 \%$ da poesia formal publicada em inglês antes do advento do verso livre, o pé utilizado é o iambo (ou jambo), o exato oposto do troqueu: uma sílaba átona seguida de uma tônica (BRITTO 2019: 36).
}

Além da estrutura métrica, há o esquema de rimas. Temos um esquema de rimas no final dos versos da segunda, quarta e quinta estrofe rimando com a sexta - que sempre traz a terminação more, seja com o refrão nevermore ou de outra forma, como, por exemplo, nothing more no primeiro verso, ou com evermore no segundo. Há também um jogo interno de rimas que ocorre no interior das primeira e terceira estrofes, "há sempre uma rima interna entre o quarto pé e o oitavo" (BRITTO 2019: 37). Para finalizar a análise das rimas:

Porém às vezes, Poe se dá ao luxo de não apenas rimar os finais dos versos, como também criar uma rima entre o final do primeiro ou

TradTerm, São Paulo, v.38, fevereiro/2021, p. 169-193

Número Especial - III JOTA

www.revistas.usp.br/tradterm 
do terceiro verso e o quarto pé do verso seguinte. É o que ocorre com a estrofe citada [a primeira estrofe], com 'rapping' no quarto pé do v.4 que rima com 'napping' e 'tapping' do v.3. Resta ainda uma última complicação: o final do v. 5 sempre repete uma parte do verso anterior - por vezes o verso quase inteiro (como ocorre na terceira estrofe), por vezes apenas a palavra final (BRITTO 2019: 3738).

Passada a análise estrutural, chamamos a atenção para o sétimo verso. No verso anterior, o eu lírico, voltando a prestar atenção ao barulho ouvido anteriormente, percebe que ele agora vinha da janela, e resolve abri-la para descobrir o que causa tal barulho. O sétimo verso marca a abertura da janela e a entrada do corvo:

Open here I flung the shutter, when, with many a flirt and flutter, In there stepped a stately Raven of the saintly days of yore;

Not the least obeisance made he; not a minute stopped or stayed

[he;

But, with mien of lord or lady, perched above my chamber door -

Perched upon a bust of Pallas just above my chamber door -

Perched, and sat, and nothing more (POE 2019).

Nossa intenção é olhar para o movimento do corvo entrando: "when, with many a flirt and flutter", temos ao mesmo tempo a descrição do corvo entrando: flutter pode ser traduzido como bater de asas, agitar, tremer, enquanto flirt, ao mesmo tempo em que pode ser traduzido como flertar também pode ser folgar ou sacudir, ou seja, está o movimento de asas do corvo, sacudindo, agitando as asas. Porém, do ponto de vista estilístico, também temos o barulho das asas com a repetição das consoantes f e l, Flirt and Flutter, som próximo da onomatopeia de asas batendo, em inglês, flap. São várias coisas acontecendo ao mesmo tempo: estrutura e semântica atuando juntas, formando um todo. E nesse 'todo' voltamos a falar de Meschonnic (2006: 8), recordando sua proposta para a renovação dos estudos da linguagem, a qual envolve, entre outros aspectos, a inter-relação entre corpo e linguagem.

TradTerm, São Paulo, v.38, fevereiro/2021, p. 169-193

Número Especial - III JOTA

www.revistas.usp.br/tradterm 
O esquema métrico e de rimas, com um entendimento convencional do ritmo, difere do esquema meschonniciano, o qual entende o ritmo de outra forma. A análise tradicional estuda separadamente os elementos do poema, entrando no descontínuo, enquanto para Meschonnic deveríamos estar lidando com um contínuo, um todo que forma um corpo. E o corpo é composto por aspectos sintáticos, semânticos e prosódicos. Meschonnic chama esses elementos unidos de 'panrítmica'.

Examinamos a seguir, a figura do corvo, a mais destacada no poema. 0 próprio corvo já é uma figura carregada de significados: "Quando pensamos em um corvo, sempre nos vêm a ideia de algo misterioso, negativo ou mágico" (FIORI 2018: 5). Ainda segundo o crítico, a relação entre humanos e animais, dentro de um conjunto de convenções culturais, é antiga, e resultou em diversas significações. Notamos que a imagem do corvo recebeu uma 'memória', e estamos aqui nos referindo a Yuri Lotman (2014: 18-19, tradução nossa):

Ainda que textos que preservem sua atividade cultural revelem a capacidade de acumular informação. Por exemplo, a capacidade de memória. Hoje em dia Hamlet não é apenas uma peça de Shakespeare, mas também a memória de todas as suas interpretações, e ainda mais, é também a memória de todos esses eventos históricos que ocorreram fora do texto, mas com as associações que podem ser evocadas com o texto de Shakespeare. ${ }^{7}$

Lotman termina dizendo que não podemos saber o que os espectadores de Shakespeare conheciam na época em que a peça foi encenada, mas não podemos esquecer o aprendido desde então. Esbarramos novamente na historicidade.

Encontramos tanto a definição científica do corvo, uma ave da família dos corvídeos, com seu habitat específico, seu tipo de alimentação e comportamento; como também as várias significações oriundas de outras áreas além da ciência. Fiori (2018: 6-16) apresenta informações sobre as

7 "Yet texts that preserve their cultural activity reveal a capacity to accumulate information, i.e. a capacity for memory. Nowadays Hamlet is not just a play by Shakespeare, but it is also the memory of all its interpretations, and what is more, it is also the memory of all those historical events which occurred outside the text but with which Shakespeare's text can evoke associations."

TradTerm, São Paulo, v.38, fevereiro/2021, p. 169-193

Número Especial - III JOTA

www.revistas.usp.br/tradterm 
relações entre humanos e corvos, como, por exemplo, as ligações conflituosas presentes em mitos ameríndios; a relação do corvo com a morte; o corvo castigado por gerador de intrigas em Metamorfoses (8 EC) de Ovídio. A ave tem papel profético na mitologia céltica: os corvos de Odin, Huginn e Munnin, são responsáveis por sobrevoar os reinos e atualizar seu mestre sobre os diversos acontecimentos; e temos o corvo do ideário cristão. De forma geral o corvo é associado ao mau agouro, de modo geral trazendo uma acepção negativa e enigmática ao poema.

Se quisermos encarar $O$ Corvo como um discurso, procurando o ritmo nele presente, além da observação da onomatopéia perdida, e assim a chamamos, pois em umas das traduções mais divulgadas em língua portuguesa, de Machado de Assis (1883) e Fernando Pessoa (1924), somos obrigados a procurar esses elementos no texto.

No caso de Pessoa (PoE 2019: 12), o sétimo verso assim se encontra:

Abri então a vidraça, e eis que, com muita negaça, Entrou grave e nobre um corvo dos bons tempos ancestrais. Não fez nenhum cumprimento, não parou nem um momento, Mas com ar solene e lento pousou sobre os meus umbrais, Num alvo busto de Atena que há por sobre meus umbrais, Foi, pousou, e nada mais.

E com Machado (PoE 2019: 19) temos:

Abro a janela, e de repente, Vejo tumultuosamente Um nobre corvo entrar, digno de antigos dias.

Não despendeu em cortesias Um minuto, um instante. Tinha o aspecto De um lord ou de uma lady. E pronto e reto, Movendo no ar as suas negras alas, Acima voa dos portais, Trepa, no alto da porta, em um busto de Palas;

Trepado fica, e nada mais.

TradTerm, São Paulo, v.38, fevereiro/2021, p. 169-193

Número Especial - III JOTA www.revistas.usp.br/tradterm 
Notamos a falta do efeito onomatopeico, um afastamento da tradução em relação à fonte, uma perda. Há um movimento do eu lírico entre o medo e incerteza versus a certeza, assim como uma espécie de delírio ao aparecer a figura de Lenore. Exemplificamos com a primeira estrofe:

Once upon a midnight dreary, while I pondered, weak and weary, Over many a quaint and curious volume of forgotten lore-

While I nodded, nearly napping, suddenly there came a tapping, As of some one gently rapping, rapping at my chamber door.

'Tis some visitor,' I muttered, 'tapping at my chamber doorOnly this and nothing more' (POE, 2019: 25).

Temos um eu lírico fraco, quase dormindo ["while I pondered, weak and weary" e "While I nodded, nearly napping, suddenly there came a tapping"], porém atento ao aqui a agora ao seu redor, tanto que percebe algum estranho visitante batendo à sua porta, "visitor, [...] tapping at my chamber door", e na segunda estrofe, esse eu lírico enfoca o passado evocando Lenore, geralmente acompanhada de elementos sobrenaturais:

Ah, distinctly I remember it was in the bleak December;

And each separate dying ember wrought its ghost upon the floor.

Eagerly I wished the morrow; -vainly I had sought to borrow

From my books surcease of sorrow-sorrow for the lost Lenore-

For the rare and radiant maiden whom the angels name LenoreNameless here for evermore (POE 2019: 25).

$\mathrm{Na}$ terceira estrofe o encanto é quebrado, e sua atenção retorna ao suposto visitante. 0 eu lírico cita o sentimento de algum terror fantástico, para na quarta estrofe recuperar sua coragem. Machado de Assis, na mesma estrofe, em nenhum momento cita algum tipo de medo ou terror. A coragem surge na quarta estrofe, porém sem alcançar o efeito do terror da anterior. Já Fernando Pessoa recupera esse movimento de terror versus coragem. Podemos comparar as diferenças no quadro abaixo:

TradTerm, São Paulo, v.38, fevereiro/2021, p. 169-193

Número Especial - III JOTA

www.revistas.usp.br/tradterm 
Quadro 1: estrofes 3 e 4 do poema The Raven e suas respectivas traduções em português.

\begin{tabular}{|c|c|c|}
\hline Edgar Allan Poe & Machado de Assis & Fernando Pessoa \\
\hline $\begin{array}{l}\text { Estrofe } 3 \\
\text { And the silken, sad, } \\
\text { uncertain rustling of each } \\
\text { purple curtain } \\
\text { Thrilled me-filled me } \\
\text { with fantastic terrors } \\
\text { never felt before; } \\
\text { So that now, to still the } \\
\text { beating of my heart, I } \\
\text { stood repeating } \\
\text { "'Tis some visitor } \\
\text { entreating entrance at my } \\
\text { chamber door- } \\
\text { Some late visitor } \\
\text { entreating entrance at my } \\
\text { chamber door;- } \\
\text { This it is and nothing } \\
\text { more." }\end{array}$ & $\begin{array}{l}\text { E o rumor triste, vago, } \\
\text { brando } \\
\text { Das cortinas ia acordando } \\
\text { Dentro em meu coração } \\
\text { um rumor não sabido, } \\
\text { Nunca por ele padecido. } \\
\text { Enfim, por aplacá-lo aqui } \\
\text { no peito, } \\
\text { Levantei-me de pronto, } \\
\text { e: "Com efeito, } \\
\text { (Disse) é visita amiga e } \\
\text { retardada } \\
\text { Que bate a estas horas } \\
\text { tais. } \\
\text { É visita que pede à minha } \\
\text { porta entrada: } \\
\text { Há de ser isso e nada } \\
\text { mais." }\end{array}$ & $\begin{array}{l}\text { Como, a tremer frio e } \\
\text { frouxo, cada reposteiro } \\
\text { roxo } \\
\text { Me incutia, urdia } \\
\text { estranhos terrores nunca } \\
\text { antes tais! } \\
\text { Mas, a mim mesmo } \\
\text { infundido força, eu ia } \\
\text { repetindo, } \\
\text { "É uma visita pedindo } \\
\text { entrada aqui em meus } \\
\text { umbrais; } \\
\text { Uma visita tardia pede } \\
\text { entrada em meus } \\
\text { umbrais. }\end{array}$ \\
\hline $\begin{array}{l}\text { Estrofe } 4 \\
\text { Presently my soul grew } \\
\text { stronger; hesitating then } \\
\text { no longer, } \\
\text { “Sir," said I, “or Madam, } \\
\text { truly your forgiveness I } \\
\text { implore; } \\
\text { But the fact is I was } \\
\text { napping, and so gently } \\
\text { you came rapping, } \\
\text { And so faintly you came } \\
\text { tapping, tapping at my } \\
\text { chamber door, }\end{array}$ & $\begin{array}{l}\text { Minh'alma então sentiu-se } \\
\text { forte; } \\
\text { Não mais vacilo e desta } \\
\text { sorte } \\
\text { Falo: "Imploro de vós, - } \\
\text { ou senhor ou senhora, } \\
\text { Me desculpeis tanta } \\
\text { demora. } \\
\text { Mas como eu, precisando } \\
\text { de descanso, } \\
\text { Já cochilava, e tão de }\end{array}$ & $\begin{array}{l}\text { E, mais forte num } \\
\text { instante, já nem tardo ou } \\
\text { hesitante, } \\
\text { "Senhor", eu disse, "ou } \\
\text { senhora, decerto me } \\
\text { desculpais; } \\
\text { Mas eu ia adormecendo, } \\
\text { quando viestes batendo, } \\
\text { Tão levemente batendo, } \\
\text { batendo por meus } \\
\text { umbrais, }\end{array}$ \\
\hline
\end{tabular}

TradTerm, São Paulo, v.38, fevereiro/2021, p. 169-193

Número Especial - III JOTA www.revistas.usp.br/tradterm 


\begin{tabular}{|l|l|l|}
\hline $\begin{array}{l}\text { That I scarce was sure I } \\
\text { heard you"-here I } \\
\text { opened wide the door;- } \\
\text { Darkness there and } \\
\text { nothing more. }\end{array}$ & $\begin{array}{l}\text { manso e manso } \\
\text { Batestes, não fui logo, } \\
\text { prestemente, } \\
\text { Certificar-me que aí } \\
\text { estais." } \\
\text { Disse; a porta escancaro, } \\
\text { acho a noite somente, } \\
\text { Somente a noite, e nada } \\
\text { mais. }\end{array}$ & $\begin{array}{l}\text { Que mal ouvi..." E abri } \\
\text { largos, franqueando-os, }\end{array}$ \\
\hline
\end{tabular}

Salientamos agora, alguns aspectos estilísticos. Voltando à carga negativa e misteriosa da ave corvo, não é apenas pela memória da palavra que estamos atuando, mas também pela forma na qual ela nos foi trazida: os adjetivos usados também entram em uma espécie de jogo de vai e volta, começando com uma carga positiva para terminar como algo negativo: é um visitor [visitante], talvez um Sir ou Madam, [senhor ou madame], "Raven of saintly days of yore" [Corvo dos santos dias de outrora] "ebony bird" [pássaro de ébano] "Ghastly grim and ancient Raven" [Corvo medonho, sombrio e antigo], "ungainly fowl" [ave desajeitada], para citar alguns exemplos. É possível observar que até o corvo varia de posição dentro dos olhos do eu lírico. O corvo ao qual temos acesso no texto é mostrado de forma incerta, errante, denunciando um eu lírico errático. Se a métrica e o sistema de rimas seguem ferrenha precisão, o eu lírico é completamente descompassado. Há uma tensão entre a forma e o que é dito. Apenas o corvo, com o seu constante 'nevermore', junto com a métrica e esquema de rimas, é consistente na poesia; não à toa ele encontra abrigo no busto de Pallas, também conhecida como Athenas, deusa grega associada à sabedoria.

Analisando sob um ponto de vista peirceano, teremos na leitura da poesia o surgimento de terceiro, o símbolo que é a representação da poesia, resultante da união dos elementos de uma primeiridade como, por exemplo, a sensação da perda amorosa, com elementos de uma secundidade: a tradução efetiva, materializada em texto. Esse elemento terciário-simbólico previsto

TradTerm, São Paulo, v.38, fevereiro/2021, p. 169-193

Número Especial - III JOTA

www.revistas.usp.br/tradterm 
pela teoria de Peirce só é possível ao estabelecer relações intertextuais ${ }^{8}$, do texto com outros textos. 0 corvo, símbolo de mau agouro, seria um exemplo de um elemento simbólico dentro da obra. Sua carga negativa é construída dentro do poema, mas também é acessada por elementos exteriores preexistentes a ele, recuperando textos outros, ou seja, caindo em uma das historicidades anteriormente citadas.

\section{Conclusão}

O símbolo está relacionado à memória, ao hábito, e está em relação direta com a terceridade, com a união de um primeiro e um segundo. Para explicar a totalidade da poesia trazendo a carga do pensar de Meschonnic, precisaríamos encarar a poesia agindo tanto com as características do ícone e da primeiridade, com as impressões difíceis de definir; assim como o índice e a secundidade, ou seja, sua materialidade física. Só que a primeiridade, secundidade, ícone e índice a que estamos nos referindo são aqueles que estão presentes dentro do terceiro, estão construindo o terceiro: o símbolo na sua terceiridade.

Uma tradução, seja para texto ou para outra materialidade, teria que considerar o corpo do texto com seu ritmo peculiar, seu jogo de tensões, o símbolo e a terceiridade que acreditamos apontar para a Historicidade.

"O ritmo é uma organização subjetiva do discurso"9 (MESCHONNIC 2006: 17). Dissemos ao início que a noção de ritmo de Meschonnic incitar a pensar a possibilidade de sentir o texto poético. A noção das três categorias de pensamento (primeiridade, secundidade e terceiridade) junto com os três elementos do signo, ícone, índice e símbolo; se nossa percepção acontece em diferentes etapas; se a materialidade do objeto observado também tem

\footnotetext{
${ }^{8}$ Deixando claro que Peirce não utiliza essa nomenclatura, trata-se de uma interpretação nossa.

${ }^{9}$ Meschonnic se baseia tanto nas ideias de enunciado quanto de ritmo de Benveniste. No caso do ritmo, não se trata da alternância entre tempo forte e fraco como se costuma pensar na música, mas o ritmo da linguagem enquanto forma em movimento, ao ser tomada pela subjetividade do sujeito no momento de sua enunciação. Seria uma "maneira particular de fluir" do texto (BENVENISTE 2005: 368).
}

TradTerm, São Paulo, v.38, fevereiro/2021, p. 169-193

Número Especial - III JOTA

www.revistas.usp.br/tradterm 
significado; se nosso fluxo de pensamento não escapa do signo, lembrando que para Peirce, quando "pensamos, então nós mesmos, tal como somos naquele momento, aparecemos como um signo" (PEIRCE 1992a, apud SANTAELLA 2004: 50); se nosso pensamento já é intersemiótico, então talvez seja possível afirmar: textos podem ser sentidos e o ritmo influencia diretamente o processo. Peirce entende que os signos estão em constante relação, compreendidos de formas diferentes em distintos momentos, resultando em certa flexibilidade de categorização, pois uma determinada palavra não será eternamente um símbolo: depende do contexto. Para esse crítico, estaríamos constantemente construindo signos, utilizando-os, em permanente tradução.

Vale destacar que o termo signo adquire diferentes conotações em cada um desses autores. Meschonnic (2010) utiliza o termo negativamente, como fórmula para dar conta do enfoque linguístico estruturalista e descontínuo, enquanto Peirce, pelo menos dentro desta nossa leitura, relaciona o signo com o corpo e com outras dimensões da linguagem.

Este estudo, porém, ainda é uma hipótese, e tal questão merece maior aprofundamento, devido a dois pontos significativos: Iniciando pelo fato de termos feito, na teoria de Peirce, um recorte necessário para iniciar a construção da hipótese, e o segundo ponto é a natureza da teoria de Meschonnic que constantemente se afasta antropomorfilismo de categorizações por julgá-las prejudiciais para a tradução e para o entendimento do funcionamento da linguagem. Em outras palavras, a linguagem parece escapar dos rótulos que the são atribuídos. A teoria somente funciona, aos olhos do pensador francês, em conjunto com a ação. Peirce objetivava criar categorias gerais, capazes de explicar os fenômenos humanos e naturais, suas categorias deveriam ser simples e abrangentes.

Por um lado, Peirce se preocupa com o signo, em categorizá-lo, para assim compreender o fenômeno linguístico, a construção de significados, o funcionamento da mente humana. Já Meschonnic busca uma forma de compreender a linguagem, procurando seu contínuo, não mais se preocupando com as categorias, olhando para a linguagem como algo com vida. Entendemos, porém, que contínuo e descontínuo se complementam. Peirce TradTerm, São Paulo, v.38, fevereiro/2021, p. 169-193

Número Especial - III JOTA

www.revistas.usp.br/tradterm 
separa as categorias, mas admite a transformação do signo, admite certo movimento, e é isso que o aproximaria de Meschonnic.

Um dos problemas que encontramos ao lidar com esses dois autores é que Peirce tentou explicar detalhadamente sua teoria, enquanto Meschonnic o fez de forma mais solta, resultando em conceitos mais elásticos, difíceis de delimitar e aplicar. Porém, quando olhamos para a poesia, os dois pontos de vista acabam por se complementar. De um lado, o enunciado, a poesia como unidade; do outro, a poesia como um símbolo. Para um signo se tornar um símbolo, é necessária uma construção de vários signos, uma complexidade e certa regularidade, entrando, nesse caso, nas historicidades citadas anteriormente.

Olhando o ritmo como organização subjetiva do discurso, entendemos que o tradutor cria uma subjetividade ao traduzir; ao mesmo tempo, ao ler o texto fonte, o tradutor está criando um interpretante, um novo signo que representa o texto original. 0 conceito de signo de Peirce também apresenta certa elasticidade, ora caindo no descontínuo e nas categorizações, ora possibilitando certa movimentação, expandindo-se para o contínuo, pois sua noção de signo é ampla, já que tanto uma palavra, quanto uma cor, ou um texto inteiro, todos esses podem ser considerados signos para Peirce.

Ambos os pensadores apresentam raciocínios complexos, mas nem por isso devem ser deixados de lado. Talvez justamente pelo fato de navegarem por lugares diferentes que seja interessante conhecer os seus estudos. Apesar dos pontos acima citados, o vislumbre da questão da subjetividade e da elasticidade de certos conceitos, como o signo de Peirce, por exemplo, esta pesquisa poderá servir como uma forma de guia, uma possível aproximação de pensamentos e porta de entrada para futuros estudos.

TradTerm, São Paulo, v.38, fevereiro/2021, p. 169-193

Número Especial - III JOTA

www.revistas.usp.br/tradterm 


\section{Referências}

Assis, M. O Corvo. In: PoE, E. A. 'O Corvo' traduções Fernando Pessoa e Machado de Assis; organização, posfácios e traduções dos ensaios Paulo Henriques Britto. São Paulo: Companhia das Letras, 2019, p. 1723

BENVENISTE, É. A noção de "ritmo" em sua expressão linguística. In.: BENVENISTE, É. Problemas de linguística geral I. Campinas: Pontes Editora, 2005, p. 361-370.

BenVEnISTE, É. O aparelho formal da enunciação. In.: Benveniste, É. Problemas de Linguística Geral II. Pontes Editores, 2006, p. 81-90.

Britto, P. H. Um Raven e dois Corvos. In: PoE, E. A. 'O Corvo' traduções Fernando Pessoa e Machado de Assis; organização, posfácios e traduções dos ensaios Paulo Henriques Britto. São Paulo. Companhia das Letras. 2019: 31-53

CAmpos, H. Da Transcriação Poética e Semiótica da Operação Tradutora. Belo Horizonte: FALE/UFMG, 2011.

CAMPOS, H. Metalinguagem e outras metas. São Paulo, Perspectiva, 2018

FIORI, F. M. 'The Crow' (1994): James O'Barr revisto por Alex Proyas. Dissertação (Mestrado em Imagem e Som) Universidade Federal de São Carlos. 2017.

GinzBuRG, C. Mitos, emblemas e sinais: morfologia e história. São Paulo: Companhia das Letras, 1989.

Lotman, Y. Universe of the Mind. A Semiotic Theory of Culture. Bloomington: Indiana University Press, 2014

MARTINS, M. S. C. Em defesa da literatura indígena: a atenção à literatura tradicional dos cantos xamânicos e das narrativas primordiais. Verbo de Minas. Juiz de Fora, v. 20, n. 36, p.122-144, ago/dez, 2019.

MARTINS, M. S. C. A tradução como procedimento poético de repetição. Rónai: revista de estudos clássicos e tradutórios. Juiz de Fora, v. 6, n. 1, p. 72-83, 2018.

MARTINS, M. S. C. Tecendo diálogos: Hang Kang, Van Gogh e Henri Meschonnic. 2020. No prelo.

Meschonnic, H. Poética do Traduzir. São Paulo: Perspectiva, 2010

MESCHONNIC, H. Linguagem, ritmo e vida. Belo Horizonte: FALE/UFMG, 2006

TradTerm, São Paulo, v.38, fevereiro/2021, p. 169-193

Número Especial - III JOTA

www.revistas.usp.br/tradterm 
NetTo, J. T. C. Semiótica, Informação e Comunicação. São Paulo: Perspectiva, 2014.

Neumann, D. A presença de Saussure e Benveniste em Henri Meschonnic. In: VII SENALE - Seminário Nacional sobre Linguagens e Ensino, 2013, Pelotas. Anais do VII SENALE. Pelotas: Editora da Universidade Católica de Pelotas, 2013. Disponível em https://docplayer.com.br/53731342-Apresenca-de-saussure-e-benveniste-em-henri-meschonnic.html. Acesso em: 19 fev. 2020.

Nöth, W.; Santaella, L. Introdução à Semiótica. São Paulo: Paulus, 2017.

Pessoa, F. O Corvo. In: PoE, E. A. 'O Corvo' - traduções Fernando Pessoa e Machado de Assis; organização, posfácios e traduções dos ensaios Paulo Henriques Britto. São Paulo: Companhia das Letras, 2019, p. 1115.

PoE, E. A. O Corvo - traduções Fernando Pessoa e Machado de Assis; organização, posfácios e traduções dos ensaios Paulo Henriques Britto. São Paulo: Companhia das Letras, 2019.

PlazA, J. Tradução Intersemiótica. São Paulo: Perspectiva, 2018

Santaella, L. O que é Semiótica. São Paulo: Editora Brasiliense, 1983

Santaella, L. O Método Anticartesiano de C.S. Peirce. São Paulo: Editora Unesp, 2004

Recebido em: 09/03/2020

Aceito em: $24 / 11 / 2020$

Publicado em fevereiro de 2021

TradTerm, São Paulo, v.38, fevereiro/2021, p. 169-193

Número Especial - III JOTA

www.revistas.usp.br/tradterm 